\title{
КОНТРОЛЬ ПОСЕЩАЕМОСТИ УЧЕБНЫХ ЗАНЯТИЙ В ВУЗЕ
}

\author{
Л. В. Степкина \\ Московский гуманитарный университет
}

Аннотация: В статье представлена информация об опыте внедрения системы контроля посещаемости учебных занятий в Московском гуманитарном университете. Охарактеризованы основные формы и механизмы контроля. Систематизируются выявленные причины неявки обучаемых на занятия, а также способы обработки и дальнейшего использования данных о посещаемости.

Ключевые слова: посещаемость; контроль посещаемости; форма контроля; учебный процесс; учебное занятие; высшее образование; Московский гуманитарный университет

\section{CONTROL OVER ATTENDANCE OF LEARNING SESSIONS AT HIGHER EDUCATIONAL ESTABLISHMENTS}

\author{
L. V. Stepkina \\ Moscow University for the Humanities
}

Abstract: The article provides information on the experience of introducing a system for control over attendance of learning sessions at Moscow University for the Humanities. The author characterizes the main forms and arrangements of control. The identified reasons for non-attendance of students are systematized, as well as methods for the processing and further use of attendance data.

Keywords: attendance; attendance control; form of control; educational process; learning session; higher education; Moscow University for the Humanities

Посещаемость учебных занятий, предполагающая физическое присутствие обучаемых на учебных занятиях и их готовность принимать активное участие в образовательном процессе, всегда являлась важным аспектом в деятельности высших учебных заведений. Посещаемость учебных занятий оказывает влияние на многие аспекты деятельности вуза, включая академическую успеваемость, воспитательный процесс, создание необходимых условий взаимодействия обучаемых и профессорско-преподавательского состава, а также функционирование механизмов обратной связи между вузом и родителями обучаемых. В конечном итоге посещаемость сказывается на имидже и дальнейшем развитии вуза, во многом определяя качество набора обучаемых в рамках приемных кампаний. 
Федеральный закон «Об образовании в Российской Федерации» от 29 декабря 2012 г. № 273-Ф3, в частности п.1.1 его статьи 43 предусматривает, что обучающиеся обязаны «добросовестно осваивать образовательную программу, выполнять индивидуальный учебный план, в том числе посещать предусмотренные учебным планом или индивидуальным учебным планом учебные занятия, осуществлять самостоятельную подготовку к занятиям, выполнять задания, данные педагогическими работниками в рамках образовательной программы» (Федеральный закон ..., Электр. ресурс). Вместе с тем, есть вопросы, не регулируемые законом об образовании, в частности, отсутствие требований к посещаемости как к обязательному условию для прохождения промежуточной аттестации.

В Московском гуманитарном университете действует «Порядок организации контроля посещаемости учебных занятий», основанный на положениях Устава МосГУ, «Правил внутреннего трудового распорядка», «Порядка организации и осуществления образовательной деятельности по образовательным программам высшего образования - программам бакалавриата, специалитета, магистратуры».

Изначально была поставлена цель не просто механического учета участия студентов в учебных аудиторных занятиях по расписанию, но и всестороннего анализа данной проблемы с дальнейшей выработкой конкретных мер по ее решению. В этой связи в процесс контроля посещаемости учебных занятий были включены также такие задачи, как анализ активности обучающихся в учебном процессе (в т. ч. в прохождении текущей и промежуточной аттестации), выявление типичных причин неявки студентов на аудиторные занятия, фиксация отклонений в реализации учебного расписания преподавателями, определение оптимальных действий и необходимых мер в работе учебных подразделений по поддержанию сознательной учебной дисциплины для всех форм обучения студентов.

С самого начала реализации «Порядка контроля посещаемости студентами учебных занятий» у всех участников процесса сформировалось понимание того, что для достижения поставленной цели требуется более тесное взаимодействие различных учебных подразделений: Учебно-методического управления (УМУ), деканатов и кафедр. В качестве форм контроля были предложены: анализ учебной документации (журналов учебных групп, журналов преподавателей, зачетно-экзаменационных ведомостей, ведомостей рубежного контроля), а также непосредственное наблюдение и учет участия студентов в аудиторных занятиях.

Текущий контроль посещаемости состоит из комплекса последовательных процедур. Учет и контроль посещаемости студентами ученых за- 
нятий осуществляют староста учебной группы, преподаватели, сотрудники деканата и специалист Учебно-методического управления. Старосты групп фиксируют в журнале посещаемости персонифицированную информацию о каждом обучающемся, указывая в журнале дату и время занятий, наименование дисциплин в соответствии с расписанием. Согласно графику предоставления документов они сдают журналы сотрудникам деканата. Специалисты деканата осуществляют контроль ведения журнала старостами групп, выясняют причины отсутствия студентов на занятиях и вносят в базу данных посещаемости учебных занятий персонифицированную информацию о посещаемости, созданную при технической поддержке Управления информационных технологий. Кроме того, в целях формирования у обучающихся наглядной картины посещаемости ими аудиторных занятий на портале МосГУ в личном кабинете студента был создан раздел «Сведения о посещаемости». Адресная информация способствует формированию у обучающихся навыков самоконтроля и улучшению взаимодействия студентов и деканатов. В личном кабинете обучающегося содержатся также сведения об академической успеваемости, портфолио обучающегося.

Специалист УМУ осуществляет постоянный контроль. Он получает от деканатов в установленной форме данные о посещаемости и анализирует их, обобщает информацию, готовит отчёты и аналитические материалы о посещаемости учебных занятий по всему Университету.

Регулярный контроль посещаемости позволяет накапливать данные о пропусках занятий. Среди основных причин неявки на занятия, помимо пропусков по болезни, - вторичная занятость студентов, обусловленная недостаточной финансовой обеспеченностью родительской семьи и необходимостью самостоятельно оплачивать обучение. Студенты могут оформить документы на индивидуальный график посещения занятий в течение одного семестра при условии отсутствия академических задолженностей и наличии справок с места работы.

В рамках реализации мер по контролю посещаемости учебных занятий выявляются студенты, которые пропускают учебные занятия без уважительных причин. В отношении нарушителей учебной дисциплины, совершивших пропуски учебных занятий без уважительных причин или не явившихся для сдачи зачетов, экзаменов и осуществления иных форм промежуточного контроля применяются соответствующие меры дисциплинарного взыскания от устного предупреждения о недопустимости прогулов учебных занятий о выговора по Университету с последующим отчислением.

С учетом данных о численности контингента обучаемых по каждому факультету и курсу, о количестве соответствующих академических групп и 
единиц учебных занятий за указанный период выводятся обобщенные показатели ожидаемых и фактических человекопосещений как в числовом, так и в процентом отношении. Эти данные имеются у всех участников образовательного процесса. Их представление и обсуждение способствуют развитию определенного духа соревновательности между факультетами, стремлению руководителей сделать свои подразделения лучше в данном отношении. Здоровая состязательность складывается между кафедрами и преподавателями, когда обсуждаются данные посещений занятий по конкретным дисциплинам у конкретного преподавателя. Это дает возможность вносить коррективы в учебную работу, отрабатывая новые подходы к проведению занятий.

Для наглядности и анализа динамики изменения параметров посещаемости по факультетам, сотрудниками Учебно-методического управления готовятся диаграммы. На приведенном ниже примере (диаграмма 1) можно проследить, на каких факультетах отмечается некоторое снижение уровня посещаемости учебных занятий, а на каких, наоборот, виден рост показателей, как правило, обусловленный целенаправленной работой деканата и кафедр. Уровень посещаемости является стабильно устойчивым, что, в свою очередь, происходит во многом благодаря пристальному вниманию Университета к управлению образовательным процессом.

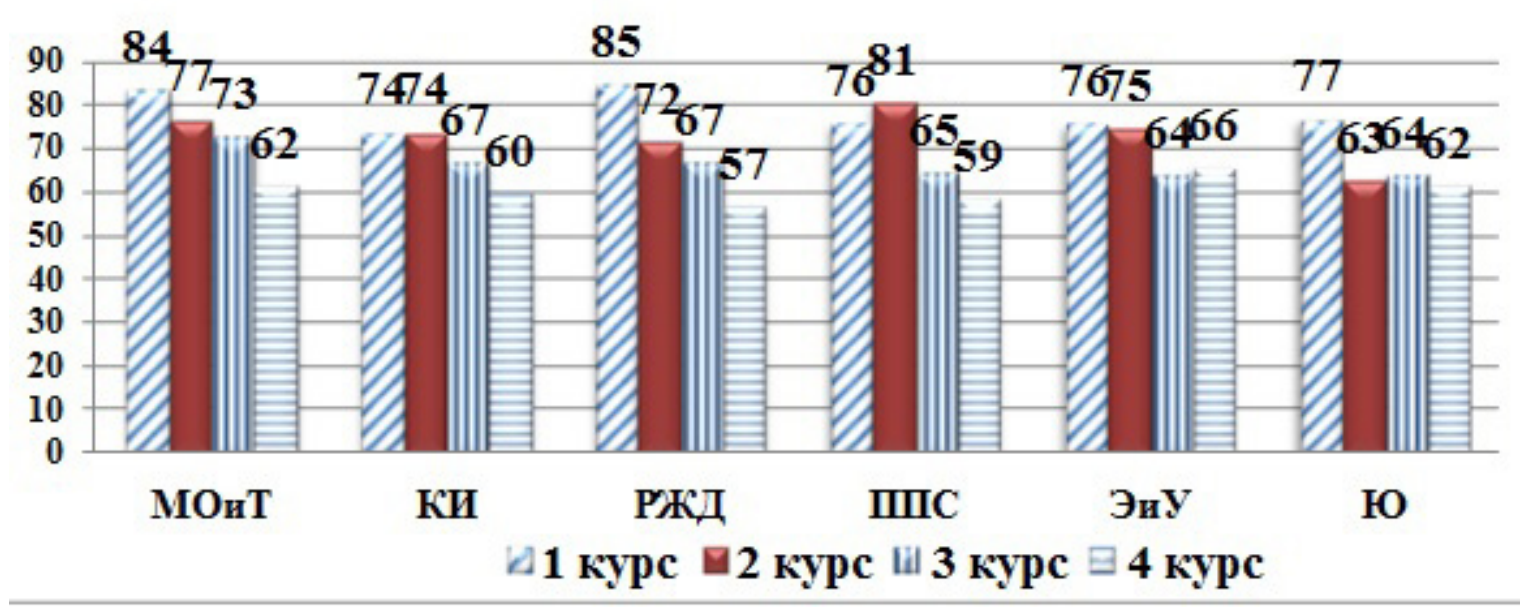

Диаграмма № 1. Состояние посещаемости учебных занятий по факультетам в начале II семестра 2017-2018 учебного года, в \%

Graph 1. The state of the attendance of learning sessions by faculty at the beginning of the 2nd semester, 2017-2018 academic year, per cent

Система контроля посещаемости учебных занятий и чёткого выполнения расписания аудиторных занятий помогает выявлять случаи нарушения 
учебного расписания со стороны преподавателей и фиксировать случаи опозданий или срывов занятий по вине преподавателей. Причины таких инцидентов устанавливаются, предпринимаются соответствующие меры.

Важную роль в функционировании системы контроля посещаемости играет информационно-разъяснительная работа, которая проводится на всех уровнях (деканаты, профессорско-преподавательский состав кафедр, студенты) и охватывает правила внутреннего распорядка, сущность контроля посещаемости и меры воздействия в случае нарушения учебной дисциплины, ведение журналов посещаемости и многое другое.

Внедрение системы контроля учебных занятий позволяет определить уровень посещаемости учебных занятий в Московском гуманитарном университете. Эта система контроля учебных занятий позволяет определять проблемные точки (студентов, склонных к нерегулярному посещению; учебные дисциплины, где имеется низкий уровень посещаемости; факультеты и учебные группы, которые отстают в данном вопросе и пр.) для последующей выработки эффективных мер по их решению. Посещаемость учебных занятий неразрывно связана с успеваемостью студентов. Усиление регулярного контроля в конечном итоге приводит к лучшим результатам в учебе (в т. ч. сокращению уровня академической задолженности).

Контроль посещаемости учебных занятий в вузе в целом способствует сохранению контингента обучаемых посредством последующего усиления индивидуальной работы со студентами и взаимодействия с родителями обучающихся, имеющих проблемы с посещаемостью учебных занятий. Достижению данной цели во многом способствует использование личного кабинета студента на информационном интранет-портале (сервере) МосГУ, информирование о дисциплинарных взысканиях, объявленных нарушителям учебной дисциплины.

Что касается перспектив этой работы, то они видятся в продолжении использования сформированной системы контроля посещаемости учебных занятий с дальнейшей ее отладкой и проведением комплексной работы по устранению выявленных в ходе контроля недостатков.

\section{СПИСОК ЛИТЕРАТУРЫ}

Федеральный закон от 29.12.2012 N 273-Ф3 (ред. от 26.07.2019) «0б образовании в Российской Федерации» [Электронный ресурс] // КонсультантПлюс. URL: http://www.consultant.ru/document/cons_doc_LAW_140174/03ed 3d9a84d233e0791495bf8600996efca437fa/ (дата обращения: 03.09.2019).

Дата поступления: 15.09.2019 2. 
Степкина Людмила Викторовна - ведущий специалист Учебно-методического управления Московского гуманитарного университета. Адрес: 111395, Россия, г. Москва, ул. Юности, д. 5. Тел: +7(499) 374-55-20. Эл. адрес: lstepkina@mosgu.ru

Stepkina Lyudmila Viktorovna, Leading Specialist, Educational Management Department, Moscow University for the Humanities. Postal address: 5, Yunosti St., Moscow, Russian Federation, 111395. Tel.: +7(499) 374-55-20. E-mail: Istepkina@ mosgu.ru

\section{Для цитирования:}

Степкина Л. В. Контроль посещаемости учебных занятий в вузе [Электронный ресурс] // Научные труды Московского гуманитарного университета. 2019. № 5. URL: http://journals.mosgu.ru/trudy/article/view/1056 (дата обращения: дд.мм.гг.). DOI: 10.17805/trudy.2019.5.7 